\title{
An Analysis of Attendance at Major League Baseball Spring Training Games
}

\author{
Michael R. Donihue \\ Colby College, michael.donihue@colby.edu \\ David Findlay \\ Colby College,dwfindla@colby.edu \\ Peter Newberry \\ Colby College
}

Follow this and additional works at: https://digitalcommons.colby.edu/faculty_scholarship

Part of the Curriculum and Instruction Commons, Econometrics Commons, Educational Assessment, Evaluation, and Research Commons, Higher Education Administration Commons, Higher Education and Teaching Commons, and the Macroeconomics Commons

\section{Recommended Citation}

Donihue, Michael R.; Findlay, David; and Newberry, Peter, "An Analysis of Attendance at Major League Baseball Spring Training Games" (2007). Faculty Scholarship. 11.

https://digitalcommons.colby.edu/faculty_scholarship/11

This Article is brought to you for free and open access by Digital Commons @ Colby. It has been accepted for inclusion in Faculty Scholarship by an authorized administrator of Digital Commons @ Colby. 


\title{
An Analysis of Attendance at
}

\section{Major League Baseball Spring Training Games}

\author{
by \\ Michael R. Donihue \\ Colby College \\ David W. Findlay \\ Colby College \\ and \\ Peter W. Newberry \\ Colby College
}

February 2005

[Please do not quote or cite without permission of the authors.]

\begin{abstract}
Michael R. Donihue
Economics Department

Colby College

Waterville, ME 04901

phone: 207.859.5232

fax: 207.859.5229

mrdonihu@colby.edu
\end{abstract}

\author{
David W. Findlay \\ Economics Department \\ Colby College \\ Waterville, ME 04901 \\ phone: 207.859.5233 \\ fax: 207.859.5229 \\ dwfindla@colby.edu
}

The authors would like to thank two anonymous referees and the editor for helpful comments on an earlier draft of this paper. Michael Donihue is an Associate Professor of Economics at Colby College. David Findlay is the Pugh Family Professor of Economics at Colby College. Peter Newberry is a 2003 graduate of Colby College. 


\title{
An Analysis of Attendance at \\ Major League Baseball Spring Training Games
}

\begin{abstract}
This paper examines the determinants of game-day attendance during Major League Baseball's 2002 spring training season in Florida. Our model of game-day attendance includes location, quality of game, and time and weather variables. A censored Tobit estimation procedure is used to estimate our model. Our results indicate that the quality of the game, average ticket price, and several location-specific factors affect attendance. Specifically, our results suggest that changes in income have no effect on attendance while increases in ticket prices cause reductions in attendance. Furthermore, the estimated price elasticity of demand for Major League Baseball during the spring training season is unitary. We also find that a number of factors unique to spring training, such as a nonresident fan base and split squads of players, significantly affect game-day attendance.
\end{abstract}

Keywords: Major League Baseball; censored Tobit; game-day attendance; spring training. 


\title{
An Analysis of Attendance at
}

\section{Major League Baseball Spring Training Games}

\begin{abstract}
That's the true harbinger of spring, not crocuses or swallows returning to Capistrano, but the sound of a bat on the ball. ${ }^{1}$
\end{abstract}

Bill Veeck, 1976

It's the fans that need spring training. You gotta get 'em interested. Wake 'em up and let 'em know that their season is coming, the good times are gonna roll. ${ }^{1}$ Harry Caray

\section{Introduction}

For many Major League Baseball fans, the unofficial start of spring begins with the arrival of pitchers and catchers by the third week of February at each team's spring training site. By the first week of March, teams with spring training sites in Florida start playing official Grapefruit League games. The teams with training sites in Arizona (i.e., those teams that play in the Cactus League) follow a similar schedule. The spring training "season" concludes by the first week of April as all teams make final roster decisions and prepare for the start of the regular season.

A quick review of the history of spring training indicates that since the mid-1960's, the number of teams playing in the Grapefruit and Cactus Leagues, ignoring the effects of expansion, has been roughly constant. ${ }^{2}$ Despite a recent increase in the number of teams playing in the Cactus League, Zipp (1997, p. 428) notes that "in the minds of many, spring training is virtually synonymous with Florida.”

Interest in spring training has changed dramatically during just the past three decades. As Friedman (1995, p. 575) notes, “games which were once casual diversions became characterized by sold-out signs, scalpers, and ever-rising ticket prices.” Newspapers now report the standings for each league while box score information and articles for each game can often be found on 
sports/news websites. In fact, several of the games are televised on national networks. Not surprisingly, web sites devoted to providing detailed information about the teams, their spring training schedules, ticket prices, ballpark information, and dining and lodging information are now available. ${ }^{3}$ The spring training season has also caught the attention of policy makers and local officials who view it as a potential source of economic development and a boost for tourism. Furthermore, the demand to host a Major League team's spring training site has, according to Zipp (1997), undoubtedly contributed to some teams' decisions to change their spring training sites and/or to build new stadiums.

In this paper, we examine a previously unexplored issue in the area of sports economics: the determinants of game-day attendance during the spring training season. The only other paper of which we are aware that examines spring training is the study by Zipp who examines the economic impact of the 1994 baseball strike on those Florida counties that hosted spring training sites in 1995. However, Zipp does not examine the determinants of attendance at individual spring training games. Given the increased interest in Major League Baseball’s spring training season by both fans and policy makers, we believe that the analysis of game-day attendance that follows provides useful evidence about the determinants of demand.

Our analysis proceeds in the following fashion. In the next section we review some of the relevant literature on attendance at major sporting events. In the third section we present a model of spring training game-day attendance. In the fourth section, we discuss our data set. In the following section we report and interpret our empirical results. The paper ends with a summary of our results and some conclusions. 


\section{Literature Review}

A number of studies have examined the determinants of attendance at sporting events for different sports and sport leagues. Peel and Thomas (1992), Wilson and Sim (1995), Czarnitzki and Stadtmann (2002), and Garcia and Rodriquez (2002) all examine the determinants of attendance at soccer games in several different soccer leagues. While Siegfried and Hinshaw (1979) and Welki and Zlatoper (1994, 1999) estimate attendance functions for U.S. professional football, Price and Sen (2003) estimate game-day attendance functions for U.S. college football. Jones, Stewart and Sunderman (1996) and Paul (2003) both investigate the determinants of demand for individual games in the National Hockey League, while Borland and Lye (1992) conduct a similar analysis for Australian Rules football. Brown, Spiro and Keenan (1991), and Burdekin and Idson (1991) estimate attendance functions for professional basketball. Noll (1974) examines the factors affecting the demand for hockey, professional basketball, U.S. professional football, and Major League Baseball.

A number of other studies focus on the determinants of attendance in professional baseball. Hill, Madura, and Zuber (1982), Marcum and Greenstein (1985), Medoff (1986), Whitney (1988), Baade and Tiehan (1990), Knowles, Sherony, and Haupert (1992), Bruggink and Eaton (1996), Kahane and Shmanske (1997), Schmidt and Berri (2002), and Butler (2002) all examine various aspects of the determinants of demand for Major League Baseball games, while Siegfried and Eisenberg (1980) estimate attendance functions for minor league baseball.

There are several results reported in the above studies that are worth highlighting. First, the effects of changes in income on attendance vary both within and across different sports leagues. In their analysis of game-day attendance in the Spanish Football League, Garcia and Rodriguez (2002) find that increases in income cause an increase in match attendance. In contrast to these 
results, Borland and Lye (1992) find that increases in income have a negative effect on attendance for Australian Rules football. Studies of attendance in baseball have also found a variety of effects of changes in income on demand. Kahane and Shmanske (1997) report results that indicate that baseball is a normal good while Bruggink and Eaton (1996) find that attendance at Major League games is an inferior good. And finally, in their studies of demand for minor league baseball and Major League Baseball, respectively, Siegfried and Eisenberg (1980) and Knowles, Sherony, and Haupert (1992) obtain results suggesting that changes in income have no effect on demand.

Second, the vast majority of the above studies also examine the effects of ticket price on attendance. While the general pattern of results indicates that higher ticket prices cause reductions in attendance, both Medoff (1986) in his study of attendance during the 1980 Major League Baseball season and Burdekin and Idson (1991) in their study of the determinants of attendance at National Basketball Association games find that attendance is unresponsive to changes in price. In the remaining studies that examine the possible price-attendance relationship, the results generally suggest that demand for professional sports is inelastic. However, Kahane and Shmanske (1997) report results indicating that demand for baseball may be unitary elastic. Furthermore, Garcia and Rodriguez (2002) find that demand for some soccer teams may be elastic.

Third, several studies examine the attendance effects of either stadium age or the longevity of a team in its current location. Bruggink and Eaton's (1996) results indicate a rather surprising effect of stadium age on baseball attendance in that attendance at American League games decreases while attendance at National League games increases as stadium age increases. Both 
Siegfried and Eisenberg (1980) and Borland and Lye (1992) obtain evidence indicating that attendance increases the longer a team has played in its current location.

And finally, a smaller number of papers have examined what effect the distance between the two competing teams' cities has on attendance. For example, in their study of game-day attendance at National League baseball games during the 1988 season, Knowles, Sherony and Haupert (1992) find that an increase in the distance between the home team's city and the visiting team's city has a negative effect on attendance.

\section{A Model of Spring Training Game-Day Attendance}

There are a number of aspects of the spring training season and, in particular, individual spring training games that differ from the regular Major League Baseball season and regular season games. First, the vast majority of spring training games are played during the day over a season that lasts just 5 weeks. Second, all games are played outdoors; there are no domed or fully roofed stadiums in the Grapefruit League. Third, given the proximity of the teams' spring training sites, it is easier for fans to travel with their favorite team when it plays games against teams whose sites are nearby.

Fourth, in order to increase the opportunity of playing time during the spring training season, each team will play a number of "split squad" games. A split squad game occurs when a team's

roster is split and each sub-roster plays against different teams on the same day. These split squad games are announced in advance and are therefore part of the spring training season schedule. It is important to note, however, that the rosters of each split squad "team" are not announced prior to game time. 
Fifth, the demand for spring training games in any spring training city may be determined more by nonresidents than by residents. For example, the demand for tickets during the regular season at a St. Louis Cardinals' home game is likely determined by economic conditions (e.g. income per capita) in the greater St. Louis area. During the St. Louis Cardinals'spring training season, however, it is less likely that the economic conditions in Jupiter, Florida (where the Cardinals play their home spring training games) will have the same relative effect on demand for tickets. As reported by Zipp (1997, p. 432), a 1991 Florida Department of Commerce study found that approximately $80 \%$ of direct spending during spring training "came from spending by nonresident fans.” More generally, there is a tourism aspect to spring training that is likely more important in influencing game-day attendance than that which exists during the regular season. And finally, the atmosphere at spring training games is far more relaxed and casual than that observed during regular season games.

The variables in previous models of game-day attendance in professional sports generally fall into one of three categories: measures of location and stadium characteristics; measures of expected game quality; and time and weather factors. The variables we use in our model of spring training game-day attendance also fall into these three categories and are defined in Table 1.

Population and stadium capacity appear in a number of other studies of game-day attendance and are both thought to have a positive effect on attendance. We also use, as an alternative to our population variable, the number of service sector workers in the home team's spring training city. The inclusion of the number of service sector workers reflects the unique nature of our study of spring training as this variable serves as a proxy for tourism in the home team's city and, therefore, as an alternative measure of each team's fan base. In the analysis that follows we 
consider this variable because, unlike regular season games, the fan base for spring training games may generally be made up of tourists. We also expect that attendance will be an increasing function of stadium capacity because larger stadiums hold more fans and, as noted by Borland and Lye (1992, p. 1054), fans may not "like being crowded together" and this is less likely to occur at larger stadiums.

Three variables are thought to have a negative effect on attendance: average ticket price; the distance between the visitor's spring training site and the home ballpark; and the age of the home team’s stadium. We include a distance variable, following Czarnitzki and Stadtmann (2002) and Peel and Thomas (1992), to capture the possible attendance by fans of the away team. We hypothesize that the greater the driving distance between the two teams' sites, the lower will be attendance given the greater cost of the away team's fans to travel to the other team's site. We also consider the age of the home team's stadium in our study to examine the impact of newer stadiums on attendance.

The effects of three of the location variables on attendance are indeterminate. First, as noted previously, while one might initially assume that demand for game-day attendance is a normal good, a number of previous studies have found that increases in per capita income can have either no effect or even a negative effect on game-day attendance for baseball. Second, the presence of two spring training sites in the same city could have at least two possible effects on attendance. On the one hand, the increased number of alternative baseball games within the same city might cause attendance at any particular game to decline. In this case, the presence of another spring training team in the same city would represent competition for a given quantity of entertainment expenditures. On the other hand, the presence of more than one team in the same city might cause the total number of nonresident fans in the area to be greater. For example, fans 
of the Minnesota Twins might attend Boston Red Sox home games in Fort Myers (where both teams have stadiums) when the Twins are playing as the visiting team in another city. In this case, we would expect attendance to be greater. Given these two competing effects, the presence of two teams in the same city will have an indeterminate effect on attendance.

Finally, we examine the effects on attendance of the number of years the home team has played in its current city. There are two possible competing effects of this variable on attendance. As a team's longevity in a given location increases, we might expect a greater number of fans to choose that area either as a vacation or retirement destination. In this case, attendance will be greater the greater is the number of years at the current location. At the same time, as noted by Siegfried and Eisenberg (1980, p. 64), "the novelty of a new team in a town is believed to cause a 'honeymoon effect,' which would yield relatively high attendance in the first few years a new team plays in a city.” For this latter case, we would expect attendance to decline over time as this "honeymoon" effect wears off. Therefore, the effect of the number of years at the current location variable on attendance is also indeterminate.

We examine a number of expected quality of game variables. All else fixed, we would expect attendance to be higher at those games where one or both of the teams has been successful in the past. We measure the success of each team by the number of division championships won during the past three regular seasons. We also use the number of games behind the division champion the home and visiting teams finished in the previous season as an additional measure of team success. An increase in the number of games behind the division winner (for either the home or visiting team) is expected to have a negative effect on attendance. We would also expect attendance to be higher at those games that feature a greater number of star players; we define star players as those players who were chosen to be on the previous year's 
All-Star teams. Furthermore, we hypothesize that games between teams from the same division will have higher attendance given the greater interest in competition between division rivals.

Split squad games, as described above, are unique to spring training. All else equal, we anticipate that a game that features a split squad team for the home and/or visiting team will not be as popular with fans because the quality of play will be lower. Furthermore, not only will the quality of play be lower for any game that features a split squad team, there will also be greater uncertainty about which players on a team's full roster will play in each split squad game. Because of this uncertainty, we also expect attendance to be lower at any game in which either team fields a split squad team.

We also include a number of team-specific dummy variables. First, we include two dummy variables that capture the effects on attendance in any game in which either of the two Florida teams (i.e., the Tampa Bay Devil Rays and the Florida Marlins) play. The construction of these two dummy variables allows for the attendance effects at home games for the two Florida teams to differ from the attendance effects at any game in which either of the two Florida teams is the visiting team. There are two possible offsetting effects on demand for any game in which either of the Florida teams play. On the one hand, demand for these games might be greater because a greater number of fans of these two teams reside in Florida and, therefore, will attend any spring training game in which the two teams play. On the other hand, the same tourism effect that we hypothesize exists for the other Grapefruit League teams likely does not exist to the same extent as it does for the two Florida teams. For example, there is little anecdotal evidence suggesting that regular season fans of either Florida club arrange vacation schedules so that they can attend spring training games for either Florida team. 
Second, we include dummy variables to measure the separate effects of home and away games for the Atlanta Braves. The Braves' relocation from Milwaukee to Atlanta in 1966 allowed the owners of the Braves to market the team as the "home team for the Southeast." Furthermore, given the relatively greater coverage of the Braves on the TBS super station, we might expect demand to be greater for all Braves games. And finally, we also include separate dummy variables to take into account the effects on attendance for New York Yankee home and away games. $^{4}$

A priori, we expect game-day attendance to be greater for night and weekend games. Weather and time factors with expected negative relationships with game-day attendance include variables for cold weather, hot weather, and rain on the day of the game. And finally, we include dummy variables for the first four weeks of the five-week spring training season to control for possible trends or weekly variations in attendance.

\section{2002 Spring Training Data}

Data for regular season Major League Baseball games are readily available and reported with great attention to detail and accuracy. Collecting data for the spring training season is considerably more difficult. Historical weather information is readily available via the Internet. Records for spring training games, however, are not well maintained and the variety of factors that influence spring training - unexpected roster changes, shortened playing times for All-Star players, and split squads to name a few - can lead to inconsistencies in reporting formats and the scope of statistics available. Much of the data for this study was collected in a real time fashion from box scores of games on the day after they were played. 
Tables 2 and 3 provide summary statistics for the variables in our study along with some additional summary statistics for each of the teams in our sample. The dependent variable in our study is the natural logarithm of the attendance for each game played by the twenty Major League Baseball teams in the Florida Grapefruit League during the 2002 spring training season. Attendance figures, as reported in the box scores, were collected for a total of 298 games. The average game-day attendance was 5,070 fans. The New York Yankees had the highest average attendance with 9,954 fans per game, while Kansas City had the lowest with 3,204.

Per capita income in 1999 and total population in the home team's city were collected from the 2000 Census. The league average, reported in the bottom row of Table 3, for these two variables was $\$ 21,889$ and 77,632 persons, respectively. The average number of service sector workers in the home cities represented by these twenty teams was $4,432 .^{5}$ The average age of a stadium was 19.7 years with an average capacity of 7,761. All teams played in stadiums that were at least 5 years old.

Our visitor proximity variable is calculated by taking the driving distance, in miles, between the home and the visiting teams' cities. The average distance the visiting team traveled during the 2002 spring training season was 72 miles; the maximum distance traveled was 250 miles (Clearwater to Jupiter). In the 2002 spring training season, two cities shared spring training sites for two teams, making the distance traveled zero miles. ${ }^{6}$

Ticket prices at spring training ballparks vary by the location of the seat in the stadium just as they do during the regular season. However, the number of tickets sold at each price is not reported, and thus we used the average ticket price at each home stadium as our ticket price variable. The average ticket price for the twenty teams in our study was $\$ 10.64$. The Atlanta 
Braves charged the highest average ticket price in 2002 at $\$ 15.75$, while the Pittsburgh Pirates had the lowest average ticket price of $\$ 7.67$.

The average number of All-Stars on each team was two, although the New York Yankees had seven. For each team, we also used the number of games it finished behind the division leader in the 2001 regular season as an alternative measure of team quality. Los Angeles had the toughest schedule, with an average of just 7 games behind among its opponents. The New York Yankees had the statistically easiest schedule, with an average of 21 games behind for those teams that traveled to Tampa to play the Yankees.

A unique feature of spring training, as noted above, is the presence of split squad games. During the 2002 spring training season, the home team fielded a split squad team in $8 \%$ of its games while the visiting team fielded a split squad team during $14 \%$ of its games. This difference in percentages is not surprising if split squad games cause lower attendance. In the extreme, a team might prefer to play all of its split squad games away from its home field so that its opponents bear the costs of the possible negative effect of split squad games on attendance.

Good weather conditions were generally the norm during the 2002 spring training season. Only 3\% of the games played had rain prior to the start of the games. Twenty percent of the games were played in relatively cold or hot conditions, with an equal number played in temperatures above 85 degrees and below 65 degrees. And finally, thirty-three percent of all games were played during weekends while only eleven percent of all games were played at night. 


\section{Empirical Results}

There were 300 games played between Major League teams in the Grapefruit League during the 2002 spring training season. ${ }^{7}$ For two of these games the number of fans in attendance was not reported in the final box scores. Thirty-eight of the 298 games in our sample were sold out; therefore, our data are right-censored in that we do not know how many fans would have attended the sold-out games had there been more seats available. To account for this, we estimated our models using the censored Tobit regression method, censoring on the capacity of the home stadium. ${ }^{8}$ We used a semilogarithmic functional form to facilitate the calculation of income and price elasticities of demand. Table 4 presents estimated coefficients and the corresponding standard errors for five alternative specifications of our model of game-day attendance.

Our initial specification in equation (1) includes all of the variables hypothesized to explain game-day attendance during spring training with the exception of the service worker and years at current location variables, which we introduce and examine in more detail in subsequent specifications. ${ }^{9}$ The estimated coefficients for the location and stadium variables are generally consistent with our a priori expectations. While the estimated coefficient on the per capita income variable is negative, it is not significantly different from zero. This result is consistent with previous studies that have found that changes in income do not have a significant effect on attendance at professional sporting events. The larger the population of the home city, however, the higher will be game-day attendance. Specifically, a one percent increase in the home city's population corresponds to a 0.13 percent increase in game-day attendance, ceteris paribus.

The insignificance of the estimated coefficient on the stadium age variable suggests that the demand for spring training games appears to be unaffected by the age of the stadium in which 
the home team plays. While owners of professional teams and even some local officials will often argue that aging stadiums have a negative effect on attendance at professional sporting events in order to make a case for the construction of a newer facility, our results for game-day attendance at spring training games do not support such claims.

Increases in the average ticket price are found to have a statistically significant negative effect on attendance with an estimated price elasticity of -1.25 . Further tests indicate that the estimated coefficient on the price variable in equation (1) and in all subsequent equations is not significantly different from -1. As noted by Kahane and Shmankse (1997, p. 429), "given that the marginal cost of an extra spectator in an unfilled stadium is negligible, the theoretical prediction is that a profit maximizing owner will attempt to maximize revenue by pricing at the point of unit elasticity.” Our results for all equations are consistent with this theoretical prediction and, we should also add, different from those reported in the majority of previous studies of attendance at sporting events where demand is found to be inelastic.

The estimated coefficient on the stadium size variable, CAPACITY, indicates that attendance is significantly higher at the larger venues where a one percent increase in stadium capacity causes a 0.63 percent increase in attendance. In contrast to our a priori expectations, the greater the driving distance between the two teams' cities, the greater will be attendance; a one mile increase in driving distance causes a 0.06 percent increase in attendance. The presence of two spring training sites in the same city does have a positive and significant effect on our dependent variable. This result suggests that the second of our two hypothesized effects of the TWOTEAM variable dominates. That is, the presence of two teams in the same city may increase the total fan base in the area and thus cause demand for all spring training games in that city to be higher. 
The results for the quality of game variables are also consistent with what we expect: attendance is generally higher at those games that feature better teams. The weaker the home team, as measured by the number of games behind the division leader it finished during the previous regular season, the lower will be attendance. According to our results, each additional game behind the division leader the home team finished in the 2001 season will cause spring training game-day attendance to fall by $1.4 \%$. The number of games behind for the visiting team is also found to have a negative and statistically significant effect on attendance. Surprisingly, we find that the presence of an additional All-Star player on the home team's and visiting team's rosters has a negative effect on attendance..$^{10}$

An interesting pattern of results emerges for our split squad dummy variables. When the home team fields a split squad team, attendance falls by $23.3 \% .{ }^{11}$ However, the insignificant coefficient on the VSS variable indicates that attendance is not significantly affected when the visiting team fields a split squad team. This combination of results suggests that if teams care only about attendance, the home team should never field a split squad team and, therefore, should play all of its split squad games on its opponent's home field. Such a strategy regarding the use of split squad games would yield, given our results, no negative effect on attendance.

The number of division championships won by the home team during the past three seasons does have, as expected, a positive effect on attendance. Each additional division championship for the home team will cause attendance to increase by 5.2\%. The number of division championships won by the visiting team, however, had no effect on attendance. And finally, we found that games between division rivals had no effect on spring training attendance.

The results for the Florida, Braves, and Yankees dummy variables yield a number of interesting results. First, the negative and significant coefficients on both the FLORIDAH and 
FLORIDAV variables are consistent with the second of our two possible explanations for the effects on attendance at any game in which either of the two Florida teams play. Specifically, despite the fact that the spring training sites for the two Florida teams are obviously in the same state in which the teams play their regular season home games, it appears as if fans for these two teams prefer to attend regular season games over spring training games. Furthermore, the same tourism effect that might exist for nearly all other teams is likely much smaller for the two Florida teams.

The results for the Braves dummy variables indicate that attendance at Braves home (away) games is $114.4 \%$ (27.4\%) higher. A similar pattern of results exists for the Yankees dummy variables where attendance at Yankees home (away) games is 149.8\% (112.2\%) higher. While the attendance implications of the estimated coefficients for the BRAVESH, YANKEESH, and YANKEESV variables might initially appear implausible, the results can be easily explained. Both the Braves and Yankees have the two largest stadiums as measured by capacity and have, on average, significantly higher attendance at home games. Furthermore, it is not impossible for attendance to more than double for a team when the Yankees visit. For example, for the Kansas City Royals average game-day attendance excluding the home games played against the Yankees was 2,836. The Royals' spring training facility in Baseball City, Florida has a capacity of 8,000. In 2002 when the Royals played the Yankees 7,992 fans attended the game, or 182\% more fans than the average attendance at all other home games. ${ }^{12}$

We will now turn our attention to the effects of weather and time factors on attendance. If the game-time temperature was below 65 degrees, attendance was 13\% lower than attendance at those games played when the temperature was between 65 and 85 degrees. At the same time, hot weather conditions appear to have no effect on attendance. The presence of rain prior to the start 
of games was also found to have no statistically significant effect on attendance. As expected, the positive and significant coefficients on the NIGHT and WEEKEND dummy variables indicate that games played during the evening or on weekends have higher attendance than games played at other times.

The negative coefficients on the week dummy variables indicate that attendance during the final week of spring training is higher than attendance during the first, second, third, and fourth weeks of the season. Despite the fact that the estimated coefficient on the WEEK3 dummy variable is not statistically significant, the magnitude of the estimated coefficients on the week dummy variables indicates that game-day attendance generally rises over the course of the spring training season. ${ }^{13}$ One possible explanation for this is that those players who are expected to be in the starting lineup in the regular season get more playing time as the spring training season progresses. Furthermore, the number of innings pitched by starting pitchers also increases over the course of the spring training season. The results reported in Table 4 are consistent with the hypothesis that a greater number of fans will attend games where regular season starting players receive more playing time.

In our second model, equation (2) in Table 4, we tried to improve the econometric specification in several ways. First, we examined more closely the effects of the quality of games variables. Specifically, we examined whether the attendance effects of the games behind, All-Star, split squad, division championship variables of the home and visiting teams and the pairs of the Florida, Braves, and Yankees variables were the same. Second, we dropped several variables that were found to have no effect on attendance in equation (1).

We tested, and could not reject at the 5\% level, the null hypothesis that the attendance effect of the number of All-Star players on the home team was equal to the attendance effect of the 
number of All-Star players on the visiting team. We, therefore, constructed a new variable, TOTSTAR, which equals the total number of All-Star players on the home and visiting teams. The results of our F-tests also indicate that the number of division championships won by the home team had an equal attendance effect as did the number of division championships won by the visiting team; consequently, we combined these two variables constructing a total division championships variable, TOTDIVCHAMP. In addition, our F-tests indicate that we can combine the two Florida and two Yankees dummy variables to create two new dummy variables, FLORIDA and YANKEES. For the games behind, split squad, and Braves variables, we could reject at the 5\% level the null hypotheses that these three pairs of variables had equal effects on attendance. In all remaining specifications, we thus continue to include the separate GBHOME, GBVIS, HSS, VSS, BRAVESH, and BRAVESA variables.

The results for equation (2) are similar to those reported for equation (1). Indeed, our results for the impact of many of the location and stadium variables and all of the quality of game and time and weather variables are remarkably robust across all model specifications in Table 4. For example, the coefficient on the per capita income variable remains statistically insignificant. While the magnitude of the estimated price elasticity fell slightly from -1.25 to -1.21 , the result continues to indicate, as discussed above, that the estimated price elasticity is not significantly different from -1. More generally, both the statistical significance and sign for all variables remain the same. For two of the newly constructed variables, FLORIDA and YANKEES, we find that attendance at any game in which either Florida team plays will be $16.8 \%$ lower while attendance at any game in which the Yankees play will be $110.9 \%$ higher.

As an additional specification, equation (3) replaces population with the number of service workers in the home city. We did this to examine one of the potentially unique aspects of 
demand for spring training games. As discussed in Section II, the demand for individual games during the spring training season may also be affected by tourists or, as described in the 1991 Florida Department of Commerce study, "nonresident fans."14 Because data for the number of tourists in each area are not available, we used the number of service workers to serve as a proxy for this alternative measure of the home team's fan base. As we found with the population variable, an increase in the number of service workers in each city causes game-day attendance to be higher. Specifically, a $1 \%$ increase in the number of service workers will cause a $0.12 \%$ increase in attendance. Perhaps just as importantly, the results in equation (3) for the remaining location, quality of game, and time and weather variables are nearly identical to those reported in equation (2). The only result in equation (3) that is different from results in the previous two equations is that the coefficient on the night dummy variable is now insignificant.

Given the extent to which the service worker and population variables are correlated (the correlation coefficient for the two variables is 0.91 ), the positive and significant coefficient on the service worker variable may simply capture indirectly the effects of population on attendance. In equation (4), rather than replace the population variable with the service worker variable, we now include a new variable, SERVWRKRSHR, which we define as the ratio of the number of service workers in a city (i.e., SERVWORK) to the city's labor force. ${ }^{15}$ The specification of equation (4) allows for a city's population and level of tourism to have separate effects on attendance. Because the results for all other variables in equation (4) are nearly identical to those in equation (3), we will focus on the attendance effects of population and our alternative measure of the service worker variable. Before we discuss these results, however, we should note that the coefficient on the night dummy variable becomes positive and significant in equation (4), as it was in the first two equations. 
The results for equation (4) indicate that population continues to have a positive effect on attendance where a one percent increase in a city's population causes a $0.11 \%$ increase in attendance. The coefficient on the service worker share variable, in contrast to our initial expectations, is negative and statistically significant. One possible explanation for this effect is that the service worker share variable, when controlling for a city's population, captures the effects of alternative entertainment activities in the area. When there are a greater number of alternative entertainment options (e.g., Disney World and Busch Gardens), attendance at spring training games, all else fixed, will be lower. The negative and significant coefficient on the SERVWRKRSHR variable is consistent with this alternative explanation.

As a final specification, we include in equation (5) a variable that measures the number of years a team has played its home games in its current location (YRSATLOC). The inclusion of this variable allows us to examine two potentially competing effects. On the one hand, the longer a team has played in the same city, the more established might be its fan base and, therefore, the greater will be attendance. On the other hand, there may exist a novelty effect of a relatively new team in a city. In this case, we would expect attendance to be highest in the early years of a team's stay in a given city but then expect attendance to decrease over time as this novelty effect wears off. The estimated coefficient on the YRSATLOC variable in equation (5) is negative and significant indicating that the latter of the two effects appears to dominate. Specifically, each additional year a team plays in its current city will cause attendance to drop by $0.23 \%$. We do not report results for equations that include both the stadium age and years at location variables because the two variables tend to measure the same phenomenon. In fact, for eleven of the twenty teams in our sample the values for the two variables are the same. A review 
of all other results in equation (5) indicates that they are nearly identical to those obtained for equation (4).

\section{Conclusions}

This paper presents an analysis of game-day attendance at Major League Baseball spring training games. The results of our analysis not only shed light on a number of issues previously examined in the literature, but also are unique in many respects relative to other models of demand for professional sports. The nature of the spring training season presents several unusual factors that come into play when modeling game-day attendance. For example, Major League Baseball's spring training season lasts just 5 weeks. During that time, teams will field split squads and fans witness shortened appearances for star players. Geography also plays a role in determining demand. The twenty teams that played in the Florida Grapefruit League during the 2002 season were all located within 250 miles of each other, with some teams playing in the same city. Furthermore, nonresidents make up a significant portion of the fan base.

The determinants of game-day attendance in our model are divided into three categories: location and stadium factors; quality of game variables; and time and weather variables. For all specifications of our attendance equation, we find that changes in income have no effect on

demand for spring training games. Consistent with other research on the economics of professional sports we find that higher ticket prices cause lower attendance. However, unlike the majority of previous studies for regular season attendance, our results are consistent with unitary price elasticity of demand for Major League Baseball spring training games. While stadium age has no effect on attendance, attendance tends to decline over time as the team's longevity in its 
current location increases. Furthermore, average game-day attendance is greater in locations that have two teams in the same city.

Controlling for game quality, we find that the more competitive a team was during the 2001 regular season the greater was game-day attendance during the 2002 spring training season. Teams that have previously won division championships also enjoy greater attendance, but division rivalries do not seem to affect attendance during the spring training season. Split squads are unique to spring training and our findings suggest that the home team should never field a split squad but should instead play all of its split squad games on its opponent's home field to maximize attendance. Furthermore, our results indicate that attendance is generally higher at any game in which the New York Yankees and Atlanta Braves play and lower at any game in which either of the two Florida teams play.

Our findings contribute to the extensive literature on demand for professional sports and, in particular, for Major League Baseball in a number of important ways. The unique nature of the data provides valuable lessons in the construction of a database of relevant variables and the definition of factors like fan base and game quality. The censored nature of the data raises the issue of appropriate econometric methods of estimation and the robustness of estimates of price and income elasticities. Finally, our results may provide some implications for economic development and policy analysis at the regional level. While our study does not provide, for example, a multiplier analysis of the impact of a new stadium on local economic activity, our results do indicate that a new stadium does not have a positive effect on spring training attendance. 


\section{Table 1. Variable Definitions}

\begin{tabular}{|c|c|}
\hline \multicolumn{2}{|c|}{ Location and Stadium Variables } \\
\hline ATTENDANCE & Number of fans that attended a game as reported in the box score \\
\hline INCOME & Per capita income of the home city as reported in the 2000 census \\
\hline POPULATION & Population of the home city as reported in the 2000 census \\
\hline SERVWORK & $\begin{array}{l}\text { Number of employees in the arts, entertainment, recreation, accommodation, and food service } \\
\text { industries }\end{array}$ \\
\hline SERVWRKRSHR & Number of service-sector employees as a share of the labor force in the home city \\
\hline STADAGE & Age of the home stadium \\
\hline YRSATLOC & Number of years the home team has played its games in its current location \\
\hline AVEPRICE & Average ticket price to attend a game \\
\hline CAPACITY & Capacity of the home stadium ${ }^{\mathrm{i}}$ \\
\hline VISPROX & Driving distance in miles from the visiting team's city to the home team's city \\
\hline TWOTEAM & $\begin{array}{l}\text { Dummy variable equal to one if the home team plays in a city that hosts a spring training site } \\
\text { for two teams }\end{array}$ \\
\hline \multicolumn{2}{|c|}{ Quality of Game Variables } \\
\hline GBHOME & Number of games behind the division leader the home team finished in 2001 \\
\hline GBVIS & Number of games behind the division leader the visiting team finished in 2001 \\
\hline HSTAR & Number of players on the home team's roster that were on either of the 2001 All-Star teams \\
\hline VSTAR & Number of players on the visiting team's roster that were on either of the 2001 All-Star teams \\
\hline TOTSTAR & Equals HSTAR plus VSTAR \\
\hline HSS & Dummy variable equal to one if the home team was a split squad \\
\hline VSS & Dummy variable equal to one if the visiting team was a split squad \\
\hline DIVCHAMPH & Number of division championships the home team won in the past three regular seasons \\
\hline DIVCHAMPV & Number of division championships the visiting team won in the past three regular seasons \\
\hline TOTDIVCHAMP & Equals DIVCHAMPH plus DIVCHAMPV \\
\hline DIVRIV & Dummy variable equal to one if the teams playing are in the same division \\
\hline FLORIDAH & Dummy variable equal to one for home games played by the Marlins or Devil Rays \\
\hline FLORIDAV & Dummy variable equal to one for away games played by the Marlins or Devil Rays \\
\hline FLORIDA & Dummy variable equal to one for all games played by the Marlins or Devil Rays \\
\hline BRAVESH & Dummy variable equal to one for home games played by the Atlanta Braves \\
\hline BRAVESV & Dummy variable equal to one for away games played by the Atlanta Braves \\
\hline YANKEESH & Dummy variable equal to one for home games played by the New York Yankees \\
\hline YANKEESV & Dummy variable equal to one for away games played by the New York Yankees \\
\hline YANKEES & Dummy variable equal to one for all games played by the New York Yankees \\
\hline \multicolumn{2}{|c|}{ Time and Weather Variables } \\
\hline COLD & Dummy variable equal to one if the game time temperature was below $65^{\circ} \mathrm{F}$. \\
\hline HOT & Dummy variable equal to one if the game time temperature was above $85^{\circ} \mathrm{F}$. \\
\hline RAIN & Dummy variable equal to one if it rained any time from 9am to game time \\
\hline NIGHT & Dummy variable equal to one if the game was played after $5 \mathrm{pm}$ local time \\
\hline WEEKEND & Dummy variable equal to one if the game was played on a Friday, Saturday, or Sunday \\
\hline WEEK1 & Dummy variable equal to one if the game was played from February $24^{\text {th }}$ to March $4^{\text {th }}$ \\
\hline WEEK2 & Dummy variable equal to one if the game was played from March $5^{\text {th }}$ to March $11^{\text {th }}$ \\
\hline WEEK3 & Dummy variable equal to one if the game was played from March $12^{\text {th }}$ to March $18^{\text {th }}$ \\
\hline WEEK4 & Dummy variable equal to one if the game was played from March $19^{\text {th }}$ to March $25^{\text {th }}$ \\
\hline
\end{tabular}

${ }^{\mathrm{i}}$ In 38 games the attendance reported in the box score exceeded the capacity of the stadium. For these games CAPACITY was set equal to the ATTENDANCE. 
Table 2. Summary Statistics

298 Observations

\begin{tabular}{|c|c|c|c|c|}
\hline Variables & Mean & Maximum & Minimum & $\begin{array}{c}\text { Standard } \\
\text { Deviation }\end{array}$ \\
\hline ATTENDANCE & $5,069.54$ & 10,361 & 1,050 & $2,207.68$ \\
\hline \multicolumn{5}{|c|}{ Location and Stadium Variables } \\
\hline INCOME & $21,997.86$ & 35,088 & 15,071 & 5,898.35 \\
\hline POPULATION & $77,887.52$ & 303,447 & 1,924 & $74,340.48$ \\
\hline SERVWORK & $4,412.15$ & 14,000 & 194 & $3,731.45$ \\
\hline SERVWRKRSHR & 13.72 & 34.68 & 8.29 & 7.729 \\
\hline STADAGE & 19.62 & 50 & 5 & 14.632 \\
\hline YRSATLOC & 18.81 & 57 & 5 & 17.683 \\
\hline AVEPRICE & 10.69 & 15.75 & 7.67 & 1.861 \\
\hline CAPACITY & $7,530.25$ & 10,361 & 5,225 & $1,171.77$ \\
\hline VISPROX & 72.14 & 250 & 0 & 51.595 \\
\hline TWOTEAM & 0.205 & 1 & 0 & 0.404 \\
\hline \multicolumn{5}{|c|}{ Quality of Game Variables } \\
\hline GBHOME & 14.35 & 43 & 0 & 13.260 \\
\hline GBVIS & 14.60 & 43 & 0 & 13.560 \\
\hline HSTAR & 1.889 & 7 & 1 & 1.418 \\
\hline VSTAR & 1.930 & 7 & 1 & 1.479 \\
\hline TOTSTAR & 3.819 & 10 & 2 & 1.942 \\
\hline HSS & 0.084 & 1 & 0 & 0.278 \\
\hline VSS & 0.138 & 1 & 0 & 0.345 \\
\hline DIVCHAMPH & 0.604 & 3 & 0 & 1.037 \\
\hline DIVCHAMPV & 0.638 & 3 & 0 & 1.055 \\
\hline TOTDIVCHAMP & 1.242 & 5 & 0 & 1.462 \\
\hline DIVRIV & 0.195 & 1 & 0 & 0.397 \\
\hline FLORIDAH & 0.097 & 1 & 0 & 0.297 \\
\hline FLORIDAV & 0.097 & 1 & 0 & 0.297 \\
\hline FLORIDA & 0.194 & 1 & 0 & 0.397 \\
\hline BRAVESH & 0.050 & 1 & 0 & 0.219 \\
\hline BRAVESV & 0.050 & 1 & 0 & 0.219 \\
\hline YANKEESH & 0.057 & 1 & 0 & 0.232 \\
\hline YANKEESV & 0.064 & 1 & 0 & 0.245 \\
\hline YANKEES & 0.121 & 1 & 0 & 0.326 \\
\hline \multicolumn{5}{|c|}{ Time and Weather Variables } \\
\hline COLD & 0.101 & 1 & 0 & 0.301 \\
\hline HOT & 0.104 & 1 & 0 & 0.306 \\
\hline RAIN & 0.034 & 1 & 0 & 0.180 \\
\hline NIGHT & 0.114 & 1 & 0 & 0.318 \\
\hline WEEKEND & 0.326 & 1 & 0 & 0.469 \\
\hline WEEK1 & 0.168 & 1 & 0 & 0.374 \\
\hline WEEK2 & 0.242 & 1 & 0 & 0.429 \\
\hline WEEK3 & 0.238 & 1 & 0 & 0.427 \\
\hline WEEK4 & 0.221 & 1 & 0 & 0.416 \\
\hline
\end{tabular}


Table 3. Home Team Statistics - Location and Stadium Variables

\begin{tabular}{|c|c|c|c|c|c|c|c|c|c|}
\hline TEAM & ATTENDANCE $^{1}$ & INCOME & POPULATION & SERVWORK & SERVWRKRSHR & CAPACITY & STADAGE & YRSATLOC & AVEPRICE \\
\hline Atlanta & 7,697 & 15,071 & 47,814 & 8,583 & 34.68 & 10,361 & 5 & 5 & 15.75 \\
\hline Baltimore & 5,296 & 27,798 & 152,397 & 10,099 & 13.05 & 8,703 & 41 & 7 & 9.00 \\
\hline Boston $^{3}$ & 7,167 & 17,312 & 48,208 & 2,657 & 12.17 & 8,098 & 10 & 10 & 9.33 \\
\hline Cincinnati & 4,731 & 23,197 & 52,715 & 3,573 & 14.44 & 7,500 & 14 & 5 & 9.00 \\
\hline Cleveland & 4,995 & 20,383 & 26,487 & 1,241 & 11.61 & 7,597 & 37 & 10 & 11.00 \\
\hline Detroit & 4,346 & 19,760 & 78,452 & 3,239 & 9.06 & 9,000 & 37 & 57 & 9.67 \\
\hline Florida & 4,082 & 19,175 & 71,382 & 3,542 & 10.21 & 8,118 & 9 & 9 & 9.40 \\
\hline Houston & 3,611 & 15,071 & 47,814 & 8,583 & 34.68 & 6,200 & 18 & 18 & 11.00 \\
\hline Kansas City & 3,204 & 15,544 & 1,924 & 194 & 26.54 & 8,000 & 15 & 15 & 9.25 \\
\hline Los Angeles & 4,457 & 30,940 & 17,705 & 1,136 & 13.91 & 6,831 & 50 & 54 & 10.00 \\
\hline Minnesota $^{3}$ & 6,092 & 17,312 & 48,208 & 2,657 & 12.17 & 7,680 & 12 & 12 & 10.50 \\
\hline Montreal $^{2}$ & 3,474 & 35,088 & 39,328 & 2,117 & 10.68 & 7,200 & 5 & 5 & 11.75 \\
\hline NY Mets & 4,764 & 18,059 & 88,769 & 3,837 & 9.29 & 7,800 & 15 & 15 & 10.33 \\
\hline NY Yankees & 9,954 & 21,953 & 303,447 & 14,000 & 9.25 & 10,287 & 7 & 7 & 13.00 \\
\hline Philadelphia & 5,066 & 22,768 & 108,787 & 5,177 & 9.59 & 7,500 & 48 & 56 & 11.50 \\
\hline Pittsburgh & 4,307 & 20,133 & 40,212 & 2,085 & 9.48 & 6,562 & 9 & 34 & 7.67 \\
\hline St. Louis ${ }^{2}$ & 6,516 & 35,088 & 39,328 & 2,117 & 10.68 & 8,443 & 5 & 5 & 11.75 \\
\hline Tampa Bay & 3,961 & 21,107 & 248,232 & 10,593 & 8.49 & 7,227 & 27 & 5 & 10.00 \\
\hline Texas & 3,211 & 18,563 & 46,451 & 1,825 & 9.71 & 6,000 & 16 & 16 & 9.00 \\
\hline Toronto & 3,363 & 23,460 & 35,691 & 1,375 & 8.29 & 6,106 & 13 & 26 & 13.83 \\
\hline $\begin{array}{l}\text { Grapefruit } \\
\text { League }^{4}\end{array}$ & 5,015 & 21,889 & 77,632 & 4,432 & 13.90 & 7,761 & 19.7 & 18.6 & 10.64 \\
\hline
\end{tabular}

${ }^{1}$ Mean Values $\quad{ }^{2}$ Share a stadium $\quad{ }^{3}$ Share a city $\quad{ }^{4}$ Averaged over the twenty teams in our sample 
Table 3. Home Team Statistics - Quality of Game Variables

\begin{tabular}{|c|c|c|c|c|c|c|c|c|c|}
\hline \multirow{2}{*}{ TEAM } & \multicolumn{2}{|c|}{ Games Played } & \multirow{2}{*}{ GBHOME $^{1}$} & \multirow{2}{*}{ GBVIS $^{1}$} & \multirow{2}{*}{ HSTAR } & \multirow{2}{*}{$\mathrm{HSS}^{1}$} & \multirow{2}{*}{ VSS $^{1}$} & \multirow{2}{*}{ DIVCHAMPH } & \multirow{2}{*}{ DIVRIV $^{1}$} \\
\hline & Home & Away & & & & & & & \\
\hline Atlanta & 15 & 15 & 0 & 12 & 2 & 0.13 & 0.20 & 3 & 0.27 \\
\hline Baltimore & 14 & 14 & 33 & 13 & 1 & 0.00 & 0.00 & 0 & 0.14 \\
\hline Boston $^{3}$ & 14 & 16 & 14 & 17 & 1 & 0.14 & 0.14 & 0 & 0.14 \\
\hline Cincinnati & 17 & 13 & 27 & 19 & 1 & 0.12 & 0.12 & 0 & 0.12 \\
\hline Cleveland & 15 & 15 & 0 & 12 & 2 & 0.13 & 0.20 & 2 & 0.27 \\
\hline Detroit & 17 & 14 & 25 & 13 & 1 & 0.06 & 0.12 & 0 & 0.29 \\
\hline Florida & 17 & 15 & 12 & 12 & 2 & 0.06 & 0.06 & 0 & 0.41 \\
\hline Houston & 13 & 14 & 0 & 8 & 3 & 0.00 & 0.23 & 2 & 0.08 \\
\hline Kansas City & 14 & 15 & 26 & 13 & 1 & 0.00 & 0.07 & 0 & 0.36 \\
\hline Los Angeles & 15 & 14 & 4 & 7 & 2 & 0.07 & 0.27 & 0 & 0.00 \\
\hline Minnesota $^{3}$ & 16 & 16 & 6 & 19 & 3 & 0.19 & 0.25 & 0 & 0.06 \\
\hline Montreal $^{2}$ & 16 & 16 & 20 & 13 & 1 & 0.13 & 0.19 & 0 & 0.38 \\
\hline NY Mets & 15 & 14 & 6 & 10 & 2 & 0.07 & 0.07 & 0 & 0.27 \\
\hline NY Yankees & 17 & 19 & 0 & 21 & 7 & 0.24 & 0.24 & 3 & 0.29 \\
\hline Philadelphia & 16 & 14 & 2 & 20 & 1 & 0.06 & 0.06 & 0 & 0.00 \\
\hline Pittsburgh & 13 & 16 & 31 & 19 & 1 & 0.08 & 0.15 & 0 & 0.08 \\
\hline St. Louis ${ }^{2}$ & 15 & 15 & 0 & 12 & 2 & 0.07 & 0.13 & 1 & 0.07 \\
\hline Tampa Bay & 12 & 14 & 34 & 17 & 1 & 0.00 & 0.08 & 0 & 0.25 \\
\hline Texas & 14 & 15 & 43 & 19 & 2 & 0.07 & 0.07 & 1 & 0.00 \\
\hline Toronto & 15 & 16 & 16 & 14 & 1 & 0.00 & 0.07 & 0 & 0.33 \\
\hline Grapefruit League $^{4}$ & 15 & 15 & 15 & 15 & 1.85 & 0.08 & 0.14 & 0.60 & 0.19 \\
\hline
\end{tabular}

${ }^{1}$ Mean Values $\quad{ }^{2}$ Share a stadium ${ }^{3}$ Share a city $\quad{ }^{4}$ Averaged over the twenty teams in our sample 
Table 4. Censored Tobit Regression Results

\begin{tabular}{|c|c|c|c|c|c|c|}
\hline $\begin{array}{l}\text { Dependent variable: } \\
\text { ATTENDANCE }{ }^{\mathrm{i}}\end{array}$ & Coef & (1) & $\begin{array}{c}\text { Std } \\
\text { Errors }\end{array}$ & Coef & $\begin{array}{r}(2 \\
\text { cients }\end{array}$ & $\begin{array}{c}\text { Std } \\
\text { Errors }\end{array}$ \\
\hline Location and Stadium Variable & & & & & & \\
\hline INCOME $^{\mathrm{i}}$ & -0.0463 & & 0.0960 & -0.0054 & & 0.0856 \\
\hline $\begin{array}{c}\text { POPULATION }^{\mathrm{i}} \\
\text { SERVWORK }^{\mathrm{i}}\end{array}$ & 0.1269 & $* * *$ & 0.0199 & 0.1337 & $* * *$ & 0.0182 \\
\hline $\begin{array}{c}\text { SERVWRKRSHR } \\
\text { STADAGE } \\
\text { YRSATLOC }\end{array}$ & 0.0012 & & 0.0017 & -0.0002 & & 0.0014 \\
\hline AVEPRICE $^{\mathrm{i}}$ & -1.2537 & $* * *$ & 0.1820 & -1.2053 & $* * *$ & 0.1742 \\
\hline CAPACITY $^{\mathrm{i}}$ & 0.6329 & $* * *$ & 0.1923 & 0.7386 & $* * *$ & 0.1373 \\
\hline VISPROX & 0.0006 & $* *$ & 0.0003 & 0.0006 & $* *$ & 0.0003 \\
\hline $\begin{array}{c}\text { TWOTEAM } \\
\text { Quality of Game Variables }\end{array}$ & 0.4299 & +++ & 0.0684 & 0.3795 & +++ & 0.0569 \\
\hline GBHOME & -0.0136 & $* * *$ & 0.0021 & -0.0142 & $* * *$ & 0.0019 \\
\hline GBVIS & -0.0040 & *** & 0.0016 & -0.0032 & $* *$ & 0.0014 \\
\hline HSTAR & -0.0533 & * & 0.0415 & & & \\
\hline VSTAR & -0.0532 & * & 0.0342 & & & \\
\hline TOTSTAR & & & & -0.0474 & ** & 0.0261 \\
\hline HSS & -0.2647 & $* * *$ & 0.0710 & -0.2621 & $* * *$ & 0.0702 \\
\hline VSS & 0.0347 & & 0.0591 & 0.0410 & & 0.0590 \\
\hline DIVCHAMPH & 0.0521 & * & 0.0350 & & & \\
\hline DIVCHAMPV & 0.0374 & & 0.0324 & & & \\
\hline TOTDIVCHAMP & & & & 0.0467 & $* *$ & 0.0247 \\
\hline DIVRIV & 0.0153 & & 0.0432 & & & \\
\hline FLORIDAH & -0.1799 & +++ & 0.0643 & & & \\
\hline FLORIDAV & -0.1842 & +++ & 0.0576 & & & \\
\hline FLORIDA & & & & -0.1836 & +++ & 0.0442 \\
\hline BRAVESH & 0.7627 & +++ & 0.1715 & 0.6964 & +++ & 0.1329 \\
\hline BRAVESV & 0.2421 & ++ & 0.1118 & 0.2355 & ++ & 0.1013 \\
\hline YANKEESH & 0.9154 & $* * *$ & 0.2791 & & & \\
\hline YANKEESV & 0.7523 & $* * *$ & 0.1684 & & & \\
\hline YANKEES & & & & 0.7462 & $* * *$ & 0.1355 \\
\hline Time and Weather Variables & & & & & & \\
\hline COLD & -0.1395 & $* *$ & 0.0660 & -0.1395 & $* *$ & 0.0657 \\
\hline HOT & -0.0701 & & 0.0599 & & & \\
\hline RAIN & 0.0081 & & 0.0922 & & & \\
\hline NIGHT & 0.0814 & * & 0.0558 & 0.0900 & $*$ & 0.0549 \\
\hline WEEKEND & 0.1780 & $* * *$ & 0.0381 & 0.1778 & $* * *$ & 0.0378 \\
\hline WEEK1 & -0.3152 & +++ & 0.0695 & -0.3049 & +++ & 0.0680 \\
\hline WEEK2 & -0.2937 & +++ & 0.0601 & -0.2858 & +++ & 0.0585 \\
\hline WEEK3 & -0.0737 & & 0.0590 & -0.0763 & & 0.0589 \\
\hline WEEK4 & -0.1118 & + & 0.0578 & -0.1053 & + & 0.0574 \\
\hline Intercept & 5.1209 & ++ & 2.2300 & 3.5980 & ++ & 1.5179 \\
\hline Adjusted $\mathrm{R}^{2}$ & & 0.70 & & & 0.7 & \\
\hline Number of Observations & & 29 & & & 29 & \\
\hline Right-censored Observations & & 38 & & & 3 & \\
\hline
\end{tabular}

One-tailed tests for significance: * 10 percent level; ** 5 percent level; *** 1 percent level Two-tailed tests for significance: +10 percent level; ++ 5 percent level; +++ 1 percent level ${ }^{\mathrm{i}}$ Variable transformed by taking the natural logarithm Censoring variable: CAPACITY ${ }^{\mathrm{i}}$ 
Table 4. Censored Tobit Regression Results (continued)

\begin{tabular}{|c|c|c|c|c|c|c|c|c|c|}
\hline \multirow{3}{*}{$\begin{array}{c}\text { Dependent variable: } \\
\text { ATTENDANCE } \\
\text { Location and Stadium Variables }\end{array}$} & \multicolumn{3}{|c|}{ (3) } & \multicolumn{3}{|c|}{ (4) } & \multicolumn{3}{|c|}{ (5) } \\
\hline & \multicolumn{2}{|c|}{ Coefficients } & \multirow[t]{2}{*}{$\begin{array}{l}\text { Std } \\
\text { Errors }\end{array}$} & \multicolumn{2}{|c|}{ Coefficients } & \multirow[t]{2}{*}{$\begin{array}{c}\text { Std } \\
\text { Errors }\end{array}$} & \multicolumn{2}{|c|}{ Coefficients } & \multirow[t]{2}{*}{$\begin{array}{l}\text { Std } \\
\text { Errors }\end{array}$} \\
\hline & & & & & & & & & \\
\hline INCOME $^{\mathrm{i}}$ & 0.0268 & & 0.0877 & -0.0693 & & 0.0880 & -0.0658 & & 0.0832 \\
\hline POPULATION $^{\mathrm{i}}$ & & & & 0.1104 & $* * *$ & 0.0200 & 0.1048 & $* * *$ & 0.0200 \\
\hline SERVWORK ${ }^{\mathrm{i}}$ & 0.1184 & $* * *$ & 0.0198 & & & & & & \\
\hline SERVWRKRSHR & & & & -0.0094 & $* * *$ & 0.0036 & -0.0111 & $* * *$ & 0.0036 \\
\hline STADAGE & -0.00004 & & 0.0015 & -0.0001 & & 0.0014 & & & \\
\hline YRSATLOC & & & & & & & -0.0023 & $* *$ & 0.0011 \\
\hline AVEPRICE $^{\mathrm{i}}$ & -1.1173 & $* * *$ & 0.1784 & -1.2350 & $* * *$ & 0.1724 & -1.2806 & $* * *$ & 0.1699 \\
\hline CAPACITY $^{\mathrm{i}}$ & 0.8277 & $* * *$ & 0.1400 & 0.6764 & $* * *$ & 0.1372 & 0.6532 & $* * *$ & 0.1353 \\
\hline VISPROX & 0.0006 & * & 0.0004 & 0.0006 & $* *$ & 0.0003 & 0.0005 & $*$ & 0.0003 \\
\hline TWOTEAM & 0.3710 & $* * *$ & 0.0585 & 0.3733 & $* * *$ & 0.0563 & 0.3311 & $* * *$ & 0.0518 \\
\hline \multicolumn{10}{|l|}{ Quality of Game Variables } \\
\hline GBHOME & -0.0133 & $* * *$ & 0.0019 & -0.0147 & $* * *$ & 0.0019 & -0.0159 & $* * *$ & 0.0019 \\
\hline GBVIS & -0.0030 & $* *$ & 0.0015 & -0.0031 & $* *$ & 0.0014 & -0.0034 & $* * *$ & 0.0014 \\
\hline HSTAR & & & & & & & & & \\
\hline VSTAR & & & & & & & & & \\
\hline TOTSTAR & -0.0443 & $* *$ & 0.0269 & -0.0456 & $* *$ & 0.0258 & -0.0511 & $* *$ & 0.0256 \\
\hline HSS & -0.2457 & $* * *$ & 0.0723 & -0.2778 & $* * *$ & 0.0695 & -0.2861 & $* * *$ & 0.0691 \\
\hline VSS & 0.0308 & & 0.0608 & 0.0539 & & 0.0585 & 0.0619 & & 0.0582 \\
\hline \multirow{2}{*}{\multicolumn{10}{|c|}{$\begin{array}{l}\text { DIVCHAMPH } \\
\text { DIVCHAMPV }\end{array}$}} \\
\hline & & & & & & & & & \\
\hline TOTDIVCHAMP & 0.0373 & * & 0.0253 & 0.0587 & $* * *$ & 0.0248 & 0.0521 & $* *$ & 0.0248 \\
\hline \multirow{2}{*}{\multicolumn{10}{|c|}{ DIVRIV }} \\
\hline & & & & & & & & & \\
\hline \multicolumn{10}{|l|}{ FLORIDAV } \\
\hline FLORIDA & -0.1700 & $* * *$ & 0.0455 & -0.1842 & $* * *$ & 0.0436 & -0.1997 & $* * *$ & 0.0438 \\
\hline BRAVESH & 0.5459 & $* * *$ & 0.1378 & 0.8629 & $* * *$ & 0.1455 & 0.8880 & $* * *$ & 0.1426 \\
\hline BRAVESV & 0.2635 & $* *$ & 0.1042 & 0.2078 & $* *$ & 0.1005 & 0.2162 & $* *$ & 0.0997 \\
\hline \multicolumn{10}{|l|}{ YANKEESH } \\
\hline \multicolumn{10}{|l|}{ YANKEESV } \\
\hline YANKEES & 0.7715 & $* * *$ & 0.1397 & 0.7108 & $* * *$ & 0.1344 & 0.7389 & $* * *$ & 0.1337 \\
\hline \multicolumn{10}{|l|}{ Time and Weather Variables } \\
\hline COLD & -0.1310 & $* *$ & 0.0676 & -0.1482 & $* *$ & 0.0648 & -0.1535 & $* * *$ & 0.0643 \\
\hline \multicolumn{10}{|l|}{ HOT } \\
\hline \multicolumn{10}{|l|}{ RAIN } \\
\hline NIGHT & 0.0678 & & 0.0563 & 0.1083 & $* *$ & 0.0546 & 0.1047 & $* *$ & 0.0543 \\
\hline WEEKEND & 0.1792 & $* * *$ & 0.0390 & 0.1784 & $* * *$ & 0.0373 & 0.1782 & $* * *$ & 0.0370 \\
\hline WEEK1 & -0.3053 & $* * *$ & 0.0701 & -0.3114 & $* * *$ & 0.0671 & -0.3121 & $* * *$ & 0.0666 \\
\hline WEEK2 & -0.2868 & $* * *$ & 0.0602 & -0.2903 & $* * *$ & 0.0577 & -0.2864 & $* * *$ & 0.0574 \\
\hline WEEK3 & -0.0803 & & 0.0606 & -0.0789 & & 0.0581 & -0.0751 & & 0.0577 \\
\hline WEEK4 & -0.1095 & * & 0.0591 & -0.1074 & $*$ & 0.0567 & -0.1030 & $*$ & 0.0562 \\
\hline Intercept & 2.7680 & $*$ & 1.5523 & 5.2209 & $* * *$ & 1.6186 & 5.6848 & $* * *$ & 1.5878 \\
\hline Adjusted $\mathrm{R}^{2}$ & & 6873 & & & 7154 & & & .7196 & \\
\hline Number of Observations & & 298 & & & 298 & & & 298 & \\
\hline Right-censored Observations & & 38 & & & 38 & & & 38 & \\
\hline
\end{tabular}




\section{References}

Baade, R. and L. Tiehen, “An Analysis of Major League Baseball Attendance, 1969-1987,” Journal of Sport and Social Issues, Vol. 14, Spring 1990, pp. 14-32.

Borland, J. and J. Lye, “Attendance at Australian Rules Football: A Panel Study,” Applied Economics, Vol. 24, Issue 9, September 1992, pp. 1053-1058.

Brown, E., R. Spiro, and D. Keenan, "Wage and Nonwage Discrimination in Professional Basketball: Do Fans Affect It?” Journal of Economics and Sociology, Vol. 50, Issue 3, July 1991, pp. 333-345.

Bruggink, T. and J. Eaton, "Rebuilding Attendance in Major League Baseball: The Demand for Individual Games,” in J. Fizel, E. Gustafson, and L. Hadley (Eds.), Baseball Economics: Current Research, Westport, CT: Praeger, 1996, pp. 9-31.

Burdekin, R. and T. Idson, "Customer Preferences, Attendance and the Racial Structure of Professional Basketball Teams,” Applied Economics, Vol. 23, January 1991, pp. 179-186.

Butler, M., “Interleague Play and Baseball Attendance,” Journal of Sports Economics, Vol. 3, No. 4, November 2002, pp. 320-334.

Czarnitzki, D. and G. Stadtmann, “The Uncertainty of Outcome versus Reputation: Empirical Evidence for the First German Football Division,” Empirical Economics, Vol. 27, Issue 1, 2002, pp. 101-112.

Friedman, M., “Spring Training,” in J. Thorn and P. Palmer (Eds.), with M. Gerschman, Total Baseball: The Official Encyclopedia of Major League Baseball, fourth edition, New York: Viking Press, 1995, pp. 573-576. 
Garcia, J. and P. Rodriguez, "The Determinants of Football Match Attendance Revisited: Empirical Evidence from the Spanish Football League,” Journal of Sports Economics, Vol. 3, No. 1, February 2002, pp. 18-38.

Halvorsen, R. and R. Palmquist, "The Interpretation of Dummy Variables in Semilogarithmic Equations,” American Economic Review, Vol. 70, No. 3, June 1980, pp. 474-475.

Hill, J., J. Madura, and R. Zuber, “The Short-Run Demand for Major League Baseball,” Atlantic Economic Journal, Summer 1982, pp. 31-35.

Jones, J., K. Stewart, and R. Sunderman, "From the Arena Into the Streets: Hockey Violence, Economic Incentives and Public Policy,” American Journal of Economics and Sociology, Vol. 55, No. 2, April 1996, pp. 231-243.

Kahane, L. and S. Shmanske, "Team Roster Turnover and Attendance in Major League Baseball,” Applied Economics, Vol. 29, 1997, pp. 425-431.

Knowles, G., K. Sherony, and M. Haupert, “The Demand for Major League Baseball: A Test of the Uncertainty of Outcome Hypothesis,” The American Economist, Vol. 36, No. 2, Fall 1992, pp. 72-80.

Marcum, J. and T. Greenstein, "Factors Affecting Attendance in Major League Baseball II: A With-in Season Analysis,” Sociology of Sport Journal, Vol. 2, 1985, pp. 72-80.

Medoff, M., "Baseball Attendance and Fan Discrimination,” Journal of Behavioral Economics, Vol. 15, Spring/Summer 1986, pp. 149-155.

Noll, R., “Attendance and Price Setting,” in Government and the Sports Business, R. Noll (Ed.), Washington, D.C.: Brookings Institution, 1974, pp. 115-157. 
Paul, R., "Variations in NHL Attendance: The Impact of Violence, Scoring, and Regional Rivalries,” American Journal of Economics and Sociology, Vol. 62, No. 2, April 2003, pp. $345-364$.

Peel, D. and D. Thomas, “The Demand for Football: Some Evidence on Outcome Uncertainty,” Empirical Economics, Vol. 17, 1992, pp. 323-331.

Price, D. and K. Sen, “The Demand for Game Day Attendance in College Football: An Analysis of the 1997 Division 1-A Season,” Managerial and Decision Economics, Vol. 24, 2003, pp. 35-46.

Schmidt, M. and D. Berri, “The Impact of the 1981 and 1994-95 Strikes on Major League Baseball Attendance: A Time-Series Analysis,” Applied Economics, Vol. 34, 2002, pp. 471478.

Siegfried, J. and J. Eisenberg, “The Demand for Minor League Baseball,” Atlantic Economic Journal, Vol. 8, No. 2, 1980, pp. 59-69.

Siegfried, J. and C. Hinshaw, "The Effect of Lifting Television Blackouts on Professional Football No-Shows,” Journal of Economics and Business, Vol. 32, No. 1, Fall 1979, pp. 1-13.

Welki, A. and T. Zlatoper, "U.S. Professional Football: The Demand for Game-Day Attendance in 1991,” Managerial and Decision Economics, Vol. 15, 1994, pp. 489-495.

Welki, A. and T. Zlatoper, “U.S. Professional Football Game-Day Attendance,” Atlantic Economic Journal, Vol. 27, No. 3, 1999, pp. 285-298.

Whitney, J. D., “Winning Games Versus Winning Championships: The Economics of Fan Interest and Team Performance,” Economic Inquiry, Vol. 26, Issue 4, October 1988, pp. 703724. 
Wilson, P. and B. Sim, "The Demand for Semi-Pro League Football in Malaysia 1989-91: A Panel Data Approach,” Applied Economics, Vol. 27, Issue 1, January 1995, pp. 131-138.

Wooldridge, J. M., Econometric Analysis of Cross Section and Panel Data, Cambridge, MA: The MIT Press, 2002, pp. 517-549.

Wooldridge, J. M., Introductory Econometrics, second edition, Mason, OH: South-Western, 2003, pp. 578-580.

Zipp, J., "Spring Training,” in Sports, Jobs, and Taxes: The Economic Impact of Sports Teams and Stadiums, Noll, R. and A. Zimbalist (Eds.), Washington, D.C.: Brookings Institution Press, 1997, pp. 427-451. 
${ }^{1}$ http://www.baseball-almanac.com/quomenu.shtml

${ }^{2}$ For an excellent summary of the history of spring training, see Friedman (1995) and Zipp (1997). More recently, in 2003 the Texas Rangers moved their site from Port Charlotte, Florida to Surprise, Arizona while the Kansas City Royals moved their site from Baseball City, Florida to Surprise, Arizona. By 2004 there were eighteen teams in the Grapefruit League and ten teams in the Cactus League.

${ }^{3}$ See, for example, www.springtrainingmagazine.com or www.springtrainingonline.com.

${ }^{4} \mathrm{We}$ are thankful to one of the referees for suggesting that we examine the separate effects of these Florida, Braves and Yankees games.

${ }^{5}$ Service workers are defined as people employed in the arts, entertainment, recreation, accommodation, and food service industries as reported in the 2000 census.

${ }^{6}$ The Boston Red Sox and Minnesota Twins play their home games in Fort Myers while in 2002 the St. Louis Cardinals and Montreal Expos shared a stadium in Jupiter.

${ }^{7}$ We do not include in our sample exhibition spring training games played between Major League teams and college teams.

${ }^{8}$ See Wooldridge (2003, pp. 578-580; and 2002, Chapter 16) for a good discussion of censored Tobit estimation in this context.

${ }^{9}$ We calculated normally distributed z-statistics for all explanatory variables and, following the rationale in section III, used one-tailed tests for all of the explanatory variables with the exception of the INCOME, SERVWRKRSHR, YEARSATLOC, TWOTEAM, FLORIDA, FLORIDAH, FLORIDAV, BRAVESH, BRAVESV, and four week dummy variables. 
${ }^{10}$ We believe that this effect of the All-Star variables on attendance may be the result of multicollinearity and the inclusion of the team-specific dummy variables. The correlation coefficient between YANKEESH and HSTAR is 0.888 and the correlation coefficient between YANKEESV and VSTAR is 0.896. Similarly, the correlation coefficient between YANKEES and TOTSTAR is 0.873. In alternative specifications in which the team-specific dummy variables are not included, the coefficients on All-Star variables were positive and statistically significant.

${ }^{11}$ As noted by Halvorsen and Palmquist (1980), the appropriate interpretation of the coefficient of a dummy variable in a semilogarithmic regression equation can be calculated as $100 \cdot\left(e^{\hat{\beta}_{d}}-1\right)$, where $\hat{\beta}_{d}$ represents the estimated coefficient of the dummy variable.

${ }^{12}$ We investigated alternative specifications of our attendance equations that did not include the Florida, Braves, and Yankees dummy variables. In those specifications we found that a one percent increase in capacity caused a $1.3 \%$ increase in attendance. This suggests that the magnitude of the effects of capacity in an equation that excludes the Braves and Yankees dummy variables will likely be biased upwards. We should also note that the estimated coefficient on the driving distance variable in these alternative specifications was insignificant in all equations.

${ }^{13}$ Anecdotally, the third and fourth weeks of spring training coincide with spring break at many colleges, universities, and public school vacations in the northeast.

${ }^{14}$ Zipp (1997, p. 432).

${ }^{15}$ We again thank the two anonymous referees for suggesting this alternative specification. 